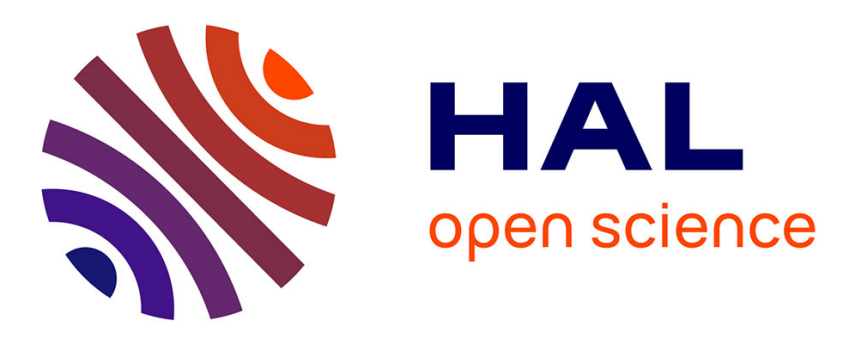

\title{
Reactivity of nanocolloidal particles -Fe2O3 at charged interfaces Part 2. Electrochemical conversion. Role of the electrode material
}

Ivan T. Lucas, Emmanuelle Dubois, Jean Chevalet, S. Durand-Vidal, Suzanne

Joiret

\section{To cite this version:}

Ivan T. Lucas, Emmanuelle Dubois, Jean Chevalet, S. Durand-Vidal, Suzanne Joiret. Reactivity of nanocolloidal particles -Fe2O3 at charged interfaces Part 2. Electrochemical conversion. Role of the electrode material. Physical Chemistry Chemical Physics, 2008, 10, pp.3274 - 3286. 10.1039/B718738F . hal-00288443

\section{HAL Id: hal-00288443 https://hal.science/hal-00288443}

Submitted on 17 Jun 2008

HAL is a multi-disciplinary open access archive for the deposit and dissemination of scientific research documents, whether they are published or not. The documents may come from teaching and research institutions in France or abroad, or from public or private research centers.
L'archive ouverte pluridisciplinaire HAL, est destinée au dépôt et à la diffusion de documents scientifiques de niveau recherche, publiés ou non, émanant des établissements d'enseignement et de recherche français ou étrangers, des laboratoires publics ou privés. 


\title{
Reactivity of nanocolloidal particles $\gamma-\mathrm{Fe}_{2} \mathrm{O}_{3}$ at charged interfaces: 2- Electrochemical conversion.
}

\author{
I. T. Lucas ${ }^{* a}$, E. Dubois ${ }^{a}$, J. Chevalet ${ }^{a}$, S. Durand-Vidal ${ }^{a}$ and S. Joiret ${ }^{\text {b }}$
}

5

Received (in XXX, XXX) 1st January 2007, Accepted 1st January 2007

First published on the web 1st January 2007

\begin{abstract}
We are interested here in the reactivity of magnetic nanoparticles at the electrode involved in the 10 electrochemical synthesis of magnetic and conductive liquids. The reactivity of charged colloidal particles occurs in two steps, first the approach toward the electrode with a possible adsorption phenomenon and secondly the electron transfer. In this paper we focus on the electrochemical behaviour of well-defined $\gamma-\mathrm{Fe}_{2} \mathrm{O}_{3}$ nanoparticles at a gold and at a mercury electrode. Particles can be electrochemically reduced at the two electrodes and can be dispersed into mercury at highly 15 negative potential. Here, we probe in particular the properties of nanoreactor of the particles, that is to say the possible conservation of their size after they have undergone the electrochemical process. By correlating complementary techniques (here Atomic Force Microscopy (AFM) observations, Raman spectroscopy and cyclic voltammetry on gold electrode) and by studying the magnetic properties of the material obtained after reduction of the particles at a mercury electrode, 20 we are able to probe both the chemical nature and the physical state of the particles once transformed. Experimental results show that under specific conditions, the particles are individually converted into iron, which justifies their use to prepare a liquid with both magnetic properties and properties of electron conduction.
\end{abstract}

\section{I- Introduction}

${ }_{25}$ This work deals with the electrochemical transformations of charged nanocolloidal particles at the electrode. The electrochemical behaviour of ions is well-known and described by theoretical models ${ }^{1}$ considering both the supply of the electroactive species to the interface by diffusion, convection, migration, and the charge transfer depending on the redox potential of the species and on the nature of the electrode. On the contrary, the description of the reactivity of charged nanoparticles is rather complicated. Firstly, one can wonder how to adequately describe the electron transfer between the electrode and such large objects (10000 30 atoms) with semiconducting properties. Does the electrochemical process concern the surface only or the whole particle? Secondly, the transport of particles (that are the electroactive species) toward the electrode can be described in the framework of the electrokinetic phenomena at the nanoscale, that is to say the motion of a charged nanoobject under an electric field. In a general way, charged colloidal particles undergo short (van der Waals forces, hydrophobic interactions) and long range interactions (electrostatics in polar medium), and their stability depends on the balance between these interactions. These 35 interactions also act on the approach of the particles to the electrode (repulsive or attractive forces with the electrode and also with the particles already adsorbed). When the particles come close enough to the electrode, an adsorption of the particles can then occur (short range interactions).

Only a few published works deal with the reactivity of nanoparticles: (I) studying electronic transfer, Heyrovsky ${ }^{2,3,4,5}$ tried to clarify the mechanisms involved in the reactivity of such objects within a series of four publications on $\mathrm{TiO}_{2}, \mathrm{SiO}_{2}$, and mixed $40 \mathrm{TiO}_{2} / \mathrm{Fe}_{2} \mathrm{O}_{3}$ colloids $(5 \mathrm{~nm}$ ) at a mercury electrode (polarography and voltammetry). (II) without any electron transfer (deposition process only), several studies ${ }^{6,7}$ deal with hematite particles $\left(\alpha-\mathrm{Fe}_{2} \mathrm{O}_{3}\right.$ : diameter $\left.\mathrm{d}=1 \mu \mathrm{m}\right)$ at a silver and at a mercury electrode and with gold nanoparticles $(\mathrm{d}=10 \mathrm{~nm})^{8}$ at a mercury electrode (III) without electrode (reduction in solution by methyl viologen), nanoparticles of hematite and goethite $(\alpha-\mathrm{FeOOH}: \mathrm{d}=50 \mathrm{~nm})$ are involved in three publications ${ }^{9,10,11}$

In this work we are interested in the electrochemical conversion of iron oxides $\left(\gamma-\mathrm{Fe}_{2} \mathrm{O}_{3}\right.$ : maghemite $)$ nanoparticles $(\mathrm{d}=12 \mathrm{~nm})$ 45 at electrodes. The deposition process has been studied in details in parallel (Lucas et al ${ }^{12}$ ). The purpose of the present work is to apprehend the evolution of the particles when they undergo the electrochemical process, and especially to know if their shape and size are preserved, thus of each nanoparticle can be considered as a "nanoreactor".

With this aim, we analyze the electrochemical transformations of the particles at two different metallic electrodes, gold and mercury which offer the following advantages:

50 (i) For gold electrodes: the conditions that allow to control the deposition process of the particles onto gold surfaces are well defined ${ }^{12}$; moreover by using ultra flat gold electrodes, it is possible to correlate multiple experimental techniques in addition to 
the electrochemical measurements, such as atomic force microscopy (AFM) and in situ Raman spectroscopy (SERS effect ${ }^{13}$ on gold). AFM is used to access the statistical determination of the size and of the number of particles adsorbed onto gold and their chemical nature is determined by spectroscopy. The results obtained on gold guide the choice of the appropriate condition to observe a behaviour of "nanoreactor" of the particles, these conditions are then used in the experiments at mercury electrodes.

5 (ii) In the case of mercury only indirect electrochemical measurements are possible, however the iron particles formed after reduction of the colloidal suspension ${ }^{14,15}$ can penetrate into the electrode, so that it is possible to obtain a dispersion of particles (magnetic) into the bulk of mercury and to study this material. Indeed, the study of the magnetic properties of the material obtained after reduction of the particles appears as a suitable way to learn about their evolution provided a sufficient amount of magnetic material is produced at the end of the electroreduction process. Producing a sufficient amount of material for the

10 analysis implies switching from the analytical experiments (using mercury drop electrode) to preparative ones (mercury pool: electrolysis).

In this paper, we first describe the colloidal suspensions used, then we sum up in a second step the conditions for particles to approach and adsorb onto the electrodes ${ }^{12}$, in view of studying their subsequent electrochemical transformation. Finally, by comparing the results obtained at a gold and at a mercury electrode, we will be able to conclude on the possible properties of 15 "nanoreactor" of the particles.

\section{II- Experiments}

\subsection{Colloidal Suspension}

\section{Synthesis}

The magnetic colloidal suspensions involved in this work are composed of nanoparticles of maghemite $\left(\gamma-\mathrm{Fe}_{2} \mathrm{O}_{3}\right)$ chemically 20 synthesized by coprecipitation of iron(II) and iron(III) in alkaline medium ${ }^{16}$. This leads to the formation of magnetite $\mathrm{Fe}_{3} \mathrm{O}_{4}$ $\left(\mathrm{Fe}^{\mathrm{II}} \mathrm{Fe}^{\mathrm{III}}{ }_{2} \mathrm{O}_{4}\right)$, which is subsequently oxidized into maghemite $\gamma-\mathrm{Fe}^{\mathrm{III}}{ }_{2} \mathrm{O}_{3}$ by $\mathrm{Fe}\left(\mathrm{NO}_{3}\right)_{3}$ in acidic medium. Due to the amphoteric properties of superficial oxides, the nanoparticles are positively charged in acidic medium and negatively charged in alkaline medium. If the conditions of $\mathrm{pH}$ and of ionic strength are appropriate $\left(\mathrm{pH}<2\right.$ and $\mathrm{pH}>12$ or I $\left.>10^{-2} \mathrm{~mol} \mathrm{~L}^{-1}\right)$, the electrostatic repulsion forces between particles prevent their aggregation under the action of the van der Waals forces, thereby stabilize the 25 suspensions in water.

The distribution in size of the nanoparticles synthesized can be described by a lognormal law ${ }^{17}$ : here $\mathrm{d}_{0}=7 \mathrm{~nm}$ and $\sigma=0.35$ after the standard synthesis. The size is then adjusted and the polydispersity reduced using a size-sorting process ${ }^{18}$ taking advantage of the properties of the phase transitions of these suspensions. The size of our particles is determined from the fit of the magnetization curves ${ }^{17}$ or from AFM measurements (see $\$ 2.3$ ). The volume fraction $\Phi_{\mathrm{vol}}$ of the particles is estimated either from a 30 chemical titration of iron $^{18}$ or from flame emission spectroscopy.

\section{Stability of the suspensions}

This system is interesting as it allows us to prepare stable colloidal dispersions while modifying the interactions between particles by the mean of several parameters: (I) the sign of the surface charge, (II) the value of the charge, (III) the ionic strength, (IV) the nature of the ions. Keeping the colloidal stability necessitates a sufficiently high charge, with a low enough ionic strength and 35 appropriate counter ions (see possible colloidal suspensions in Table1). The 'stabilizing' counter ions, usually monovalent ions, allow us to obtain stable dispersions in the $\mathrm{pH}$ range indicated. Indeed, divalent counter ions are usually 'flocculating' ions because they strongly screen the electrostatic interactions. As well, small counter ions can be flocculating ions, as $\mathrm{Na}^{+}$in alkaline medium. Note that, below $\mathrm{pH}=1.5$, iron oxides are not thermodynamically stable and start to dissolve but the kinetics of dissolution is slow enough to perform experiments. The colloidal stability is achieved neither at extreme pH values, because the

40 ionic strength becomes too high, nor between $\mathrm{pH}=3.5$ and $\mathrm{pH}=10.5$ because the surface charge density of the particles is too low ${ }^{19}$. By coating the surface with small citrate molecules ( $\left.\mathrm{OOC}-\mathrm{C}(\mathrm{OH})-\left(\mathrm{CH}_{2} \mathrm{COO}{ }^{-}\right)_{2}\right)$, a shift of the point of zero charge ${ }^{20}$ to low $\mathrm{pH}$ occurs and stable dispersions can be obtained for $\mathrm{pH}$ higher than 3.5. 


\begin{tabular}{|c|c|c|c|c|c|}
\hline \multirow[b]{2}{*}{ Particles } & \multirow{2}{*}{$\begin{array}{l}\text { pH range } \\
\text { of stability }\end{array}$} & \multicolumn{2}{|c|}{ Counter-ions } & \multicolumn{2}{|c|}{ Adsorption } \\
\hline & & Stabilizing & Not stabilizing & Onto & $\stackrel{\text { Onto }}{\text { modified gold }}$ \\
\hline $\mathrm{OH}_{2}{ }^{+}$ & $1.0-3.5$ & $\begin{array}{c}\mathrm{NO}_{3}^{-} \\
\mathrm{ClO}_{4}^{-} \\
\text {p-Tol-SO } \\
-{ }^{-}\end{array}$ & $\begin{array}{l}\mathrm{Cl}^{-} \\
\mathrm{SO}_{4}{ }^{2-} \\
\mathrm{PO}_{4}{ }^{3-}\end{array}$ & Yes & No \\
\hline & 4.0-10.0 & $\begin{array}{c}\mathbf{N a}^{+}{ }^{+} \\
\mathbf{N H}_{4}^{+} \\
\mathbf{T M A}^{+}\end{array}$ & $\begin{array}{l}\text { Divalent } \\
\text { cations }\end{array}$ & No & Yes \\
\hline & 10.0-13.0 & $\underset{(\operatorname{alkyl})_{\mathbf{n}} \mathbf{N}^{+}}{\mathbf{T M A}^{+}}$ & $\mathrm{Na}^{+}$ & No & $\begin{array}{l}\text { No possible } \\
\text { modification }\end{array}$ \\
\hline
\end{tabular}

Table 1: Summary of the different possible colloidal systems. From left to right: schematized surface showing the sign of the charge (with L: citrate ligand), $\mathrm{pH}$ range of stability, counter ions appropriate to obtain stable dispersions (stabilizing) or not (not stabilizing), ability to adsorb the particles on bare gold or gold modified with poly-L-lysine $(+)(\mathrm{pKa} \sim 9$, thus possible modification only for $\mathrm{pH}<9)$.

\subsection{Approach and adsorption on surfaces}

The electrochemical transformation of nanoparticles, which are here the electroactive entities, implies that the particles come to the electrode, which is not systematic and constitutes an important difference as compared to usual ionic systems. Previous studies have shown that particles approach and adsorb depending on the conditions.

${ }_{10}$ Lucas and al ${ }^{12}$, probing the influence of different factors on the approach of particles near charged substrates, in particular the effect of the potential applied to a conductive substrate, worked with different conductive materials (gold, mercury, highly oriented pyrolytic graphite: HOPG, glassy carbon: GC...). They pointed out several important points that we summarize here: (I) no electrochemical response is observed when no previous adsorption of the particles occurs onto the electrode. This adsorption occurs if the particles come close enough to the electrode. The possibility for particles to approach to the electrode depends on the

15 interactions between the electrode and the particles, on the interactions between the particles in the bulk solution and those already adsorbed and on the nature of the electrode. (II) At low ionic strength, positive particles do not approach to the mercury surface and the approach of the negative particles depends on the potential applied to the surface of the electrode. At high ionic strength $\left(0.1 \mathrm{~mol} \mathrm{~L}^{-1}\right)$, negative particles approach whatever the potential applied to the mercury electrode; positive particles also approach, however their adsorption rate is low. (III) Positively charged particles in acidic medium adsorb onto gold substrates 20 although the electrostatic interactions are not favourable, and negatively charged particles can not approach whatever the potential applied at the surface of the electrode, even when it is extremely positive. A positively charged polyelectrolyte as poly-L-Lysine previously adsorbed onto the gold surface (for $\mathrm{pH}$ values lower than 9: pKa of lysine $=9$ ), prevents the adsorption of positively charged particles and makes exclusively possible the deposition of particles covered with citrate molecules (-). These results are summarized in Table. (IV) When the approach is possible, an accumulation phenomenon onto gold ${ }^{12}$ and onto mercury

25 electrodes occurs with positively and negatively charged particles respectively. Once deposited onto the electrode, the short range interactions avoid the particles to desorb from the electrode (irreversible adorption ${ }^{12}$ ) even if the charge of the particles reverses by changing the $\mathrm{pH}$ of the electrolyte. (V) Near the saturation state of the surface of the electrode, the interactions between the particles already adsorbed and the wandering particles near the electrode hinder the adsorption of other particles, resulting in a lowering of the adsorption rate when the coverage increases and then to a saturation of the coverage, the value of which increases 30 with the ionic strength. (VI) Since the particles are the electroactive species, the stability of the colloidal suspension has to be maintained during the electrochemical measurements. If the particles precipitate they no longer adsorb.

In the following, we take advantage of the irreversible adsorption of the particles to separate the deposition step of the particles from their electrochemical transformations. That allows controlling perfectly the deposition rate onto both mercury and gold electrode, and then to observe the electrochemical transformation in both alkaline and acidic media. Moreover, it allows us to

35 choose the coverage of the surfaces adapted to the experimental techniques performed onto gold in this study, AFM or Raman spectroscopy.

\subsection{Study of the electrochemical transformation}

Electrodes

In order to couple several kinds of observations, the electrochemical behavior of the particles has been tested on several solid 40 electrodes: HOPG, GC, silver (Ag) and gold. The electroactivity domains of $\mathrm{Pt}$ and $\mathrm{Ag}$ are too narrow for observing the transformations of the particles. The roughness of GC is not convenient for AFM detection of nanoparticles. HOPG although perfectly adapted to AFM and electrochemical measurements, is too hydrophobic, which results in the modification of the structure of the deposits. Because gold is electrochemically stable over a relatively large range of applied potential $(-1.8 \mathrm{~V},+0.6$ 
$\mathrm{V} / \mathrm{SCE}$ at $\mathrm{pH}=3$ ) it is preferentially used as a working electrode. Moreover AFM and Raman spectroscopy can be performed on gold provided ultra flat surfaces are used (see §AFM measurements). However, the fragility of the gold layer (20 - $40 \mathrm{~nm})$ does not allow the electrode to be used several times. In practice, when electrochemical measurements are performed alone (without the need of correlation with AFM or other techniques), the ultra flat gold electrode is replaced by a polycrystalline gold electrode 5 (a wire of diameter $\mathrm{d}=1.5 \mathrm{~mm}$ embedded in a Teflon body) that allows an easy probing of the redox conversion of the particles. After each measurement, the electrode is carefully polished with alumina $(0.05 \mu \mathrm{m})$, and then rinsed with water. Several electrochemical cycles are performed on the two types of working electrodes in dilute acid electrolyte until a reproducible current baseline is obtained. In addition to these experiments on solid surfaces of gold, a hanging mercury drop electrode (HMDE) is used for analytical experiments and a mercury pool is used for preparative electrolysis of the particles.

\section{AFM}

AFM measurements are performed to check the presence of the particles adsorbed at the surface of the gold electrode after the electrode was dipped into the colloidal suspension. By correlating atomic force microscopy (AFM) and the electrochemical measurements, it is possible to follow in parallel the evolution of the structure of the deposits at the surface of the electrode when they are electrochemically modified. The deposits of particles onto the electrode can be imaged by Atomic Force Microscopy

15 (AFM) provided that the roughness of the electrodes is much lower than the particles size $(<1 \mathrm{~nm})$. The method used to obtain a roughness of the gold surfaces less than $0.5 \mathrm{~nm}$ is well known and described in ${ }^{21}$ ("ultra flat template stripped surface"). However, AFM imaging reveals the presence of numerous holes on the surface that are inherent to the elaboration protocol. Thus, we used "commercial" substrates (ACM France) consisting in a layer of gold deposited on silicon wafers by magnetron sputtering. The ultra flat gold surfaces are electrically connected and placed in a home made electrochemical cell to check their electrochemical 20 response.

AFM images are obtained using a "Digital Instrument Nanoscope III" system, operating in oscillating mode to reduce intrusive effect of the imaging process and employing silicon cantilevers with a typical resonance frequency of $300 \mathrm{KHz}$ (Nanosensors). In liquid, intrusive effect of the imaging process on "physisorbed" particles is too important with respect to particles adhesion forces; this leads to lateral motion of these particles which are removed from the surface even if they are adsorbed onto polymer 25 pre-treated surfaces. Thus, measurements in liquid (in situ) are not successful even conducted in the oscillating mode. Consequently the substrates, after deposition of particles, have to be rinsed with water and dried before AFM observations (performed in air).

\section{Electrochemical measurements}

Cyclic voltammetry is performed using a "Power lab station" from "ADinstrument Co". The different working electrodes 30 described above are associated with a calomel or $\mathrm{Ag} / \mathrm{AgCl}$ reference electrode and with a platinum counter electrode (details will be given in the legend of the figures).

As explained above, the difficulty encountered with these systems lies on the approach and on the adsorption of the nanoparticles to the electrode. If particles adsorb, reactions at the electrode are possible, however adsorption and reaction could occur at the same time; moreover, particles no longer adsorb if destabilization of the suspension occurs due for example to the presence of 35 new species formed. Therefore we take advantage of the irreversible adsorption properties of negative particles onto mercury as well as of positive particles onto gold, to separate the deposition process and the electrochemical measurements. Depending on the type of measurement performed, electrochemical technique or AFM, we control the coverage of the electrode by adjusting the $\mathrm{pH}$ and the ionic strength of the colloidal suspension ${ }^{12}$ :

a) To observe measurable currents related to the electrochemical conversion of the particles, the amount of particles adsorbed at 40 the surface of the electrode must be high. Dispersions of particles in acidic solutions at $\mathrm{pH}=1$ or at $\mathrm{pH}=3$ and $\mathrm{I}=0.1 \mathrm{~mol} \mathrm{~L}{ }^{-1}$ lead to a dense coverage at the surface of the electrode after only a few minutes (typically 5 minutes) at the open circuit potential (OCP). b) To correlate the oxido-reduction potentials and the modification of the particles, we associate electrochemical and AFM measurements. However, Lucas et al showed that AFM is not suitable to determine the amount of adsorbed particles when the coverage of the substrate reaches the saturation state. To perform an accurate statistical determination of the size of the 45 particles, the deposition step is performed in colloidal suspensions at low volume fraction $\left(\Phi_{\text {vol }}(\%)=10^{-3}\right)$, at low ionic strength $\left(\mathrm{I}=10^{-3} \mathrm{~mol} \mathrm{~L}^{-1}, \mathrm{pH}=3\right)$ at the OCP and for short time of deposition $(30 \mathrm{~s})$. AFM imaging of the deposition is realized just after the substrate has been rinsed with a solution at $\mathrm{pH}=3$ and has been dried. The structure of the deposit revealed by AFM (Figure 1 ) is reproducible, it corresponds to $200 \pm 15$ particles per square micrometer. 

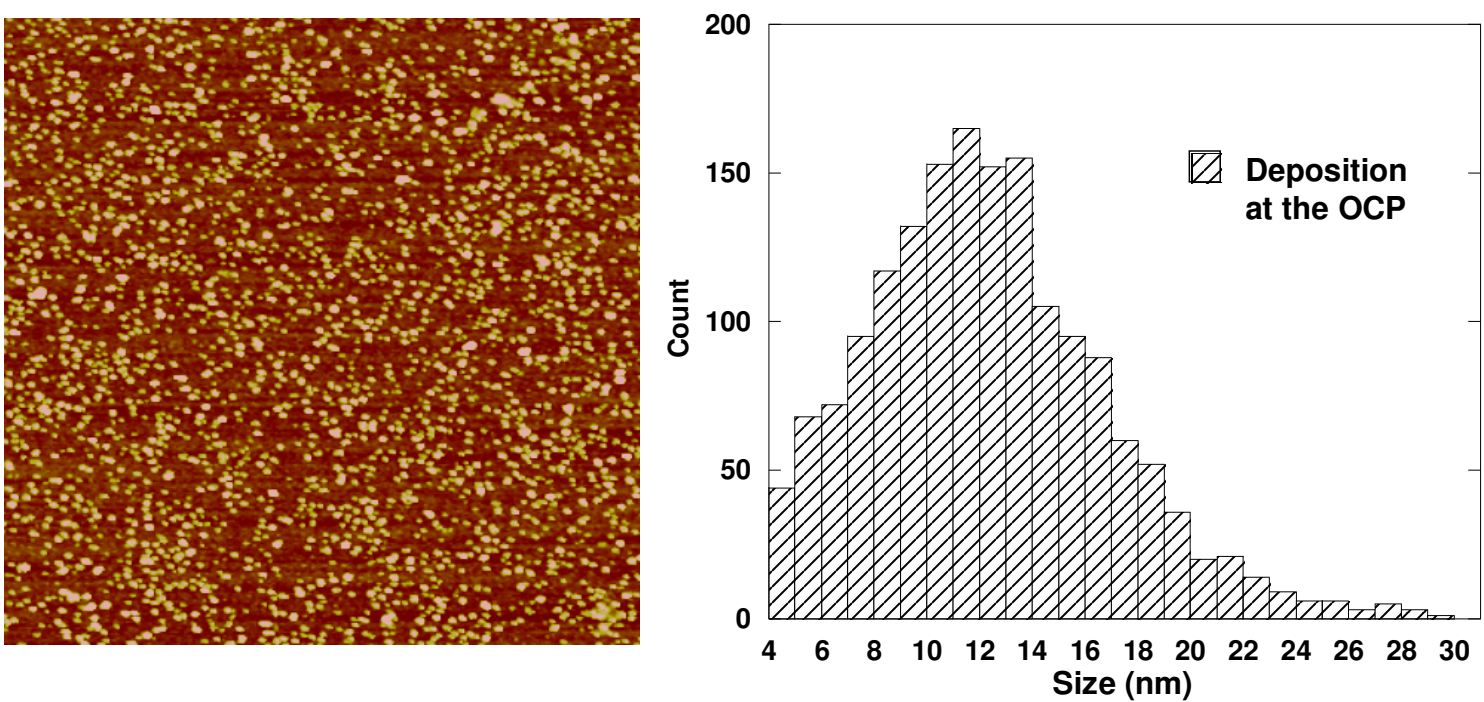

Figure 1: AFM picture of iron oxide nanoparticles, adsorbed onto a gold surface (mean roughness $<0.5 \mathrm{~nm}$ ), performed in oscillating mode (area: $3 \mu \mathrm{m} \times 3 \mu \mathrm{m}$, coverage: 200 particles $\mu \mathrm{m}^{-2}$ ). The size distribution of the particles established on 2000 particles sample exhibits a peak that corresponds to the most probable diameter $\mathrm{d}=12 \mathrm{~nm}$ (maximum of the distribution).

\section{In situ Raman spectroscopy: SERS effect}

The Raman spectra are recorded with a Labram from Jobin-Yvon Horiba with the following technical characteristics: excitation laser beam (HeNe $\lambda=632.8 \mathrm{~nm}, 100 \mu \mathrm{W}$ ), CCD detector, objective x 50 ULWD Olympus. Surface enhanced Raman scattering effect (SERS) is acquired by using rough gold substrates prepared by resistive evaporation (epitaxial growth of the gold layer, 10 thickness $25-60 \mathrm{~nm}$ ) on freshly cleaved mica heated at $300^{\circ} \mathrm{C}^{13}$. Prior to use, the Au films are flame annealed.

Dense deposits of particles are achieved onto gold surfaces by plunging the substrate in an acidic colloidal suspension $\left(\mathrm{HClO}_{4} \mathrm{pH}\right.$ $=1$ or $\left.\mathrm{HClO}_{4} \mathrm{pH}=3+\mathrm{NH}_{4} \mathrm{ClO}_{4} 0.1 \mathrm{~mol} \mathrm{~L}-1, \Phi_{\mathrm{vol}}(\%)=0.5\right)$ during five minutes. Then substrates are rinsed with $\mathrm{HClO}_{4} \mathrm{pH}=3$ and immediately covered with the electrolyte used for in situ Raman spectroscopy: the spectra and the electrochemical measurements are then recorded simultaneously in $\mathrm{HClO}_{4} \mathrm{pH}=3$, TMAOH $\mathrm{pH}=11$ and also in a borate buffer solution $\mathrm{pH}=8.4$ $15\left(0.05 \mathrm{~mol} \mathrm{~L}^{-1} \mathrm{H}_{3} \mathrm{BO}_{3}+0.0125 \mathrm{~mol} \mathrm{~L}^{-1} \mathrm{Na}_{2} \mathrm{~B}_{4} \mathrm{O}_{7} .10 \mathrm{H}_{2} \mathrm{O}\right)$.

Note that the SERS effect especially concerns the surface of the particles so that it is difficult to know if the whole volume of the particles is transformed during their electrochemical process. Moreover, enhancement intensity on gold depends on evaporation parameters and flame annealing conditions, thus it is possible to compare spectra intensities recorded on the same film but not on two different samples.

\section{${ }_{20}$ III- Study of the electrochemical conversions: Results and discussion}

\subsection{Probing of the "nanoreactor" properties of the particles at a gold electrode}

In order to probe the "nanoreactor" properties of the particles, we study the modifications of the deposited particles as a function of the $\mathrm{pH}$ of the electrolyte (acidic and alkaline media) and of the potential. Raman spectroscopy performed on gold substrate after deposition of the particles (see \$2.3) brings information on the chemical nature of the particles before and after the 25 electrochemical process, and AFM measurements allows to check the possible change of the particles size.

\subsubsection{Acidic medium}

Since particles only adsorb onto gold under acidic condition, we first investigate the behaviour of the particles in acidic media. In a first step, we probe the chemical nature of the deposited particles onto the gold electrode before any electrochemical transformation. In a second step, by comparing the voltammogram performed with particles and with iron ionic species, we 30 establish the link between the different oxido-reduction peaks that occur during the potential scan with the possible modifications of the particles.

a) Deposits at the OCP

A first Raman spectrum is performed directly in the colloidal suspension and gives the typical spectrum expected for maghemite ${ }^{13}$ (Figure 2a). Then this spectrum, used as reference, is compared to the spectra obtained on gold electrodes in $\mathrm{HClO}_{4}$ at $\mathrm{pH}^{2} 3$ 35 after deposition of particles at the OCP as described above. Figure $2 b$ shows a spectrum of gold surface after deposition of particles $($ at $\mathrm{pH}=1$ ) covered with electrolyte (perchloric acid at $\mathrm{pH}=3$ ). This spectrum exhibits several bands corresponding to maghemite, but presenting a lower intensity (max at 50cps) than the one in Figure 2 a $(120 \mathrm{cps})$ and also a high intensity band at $250 \mathrm{~cm}^{-1}$. This latter band is commonly assumed ${ }^{22}$ to be due to perchlorate interaction with gold in SERS conditions for polarization of the electrode greater than $-200 \mathrm{mV}$. We checked in this work that no band appears at the OCP when no particles are 
adsorbed on the electrode (using only $\mathrm{HClO}_{4}$ at $\mathrm{pH}=3$ to cover the electrode surface), therefore this band is attributed to the adsorbed particles. Moreover, whereas we did not reveal any significant influence of the $\mathrm{pH}$ on the intensity of the bands associated to $\gamma-\mathrm{Fe}_{2} \mathrm{O}_{3}$, if deposition is performed with a colloidal suspension in $\mathrm{HClO}_{4}$ at $\mathrm{pH}=3\left(+\mathrm{NaClO}_{4} 0.1 \mathrm{~mol} \mathrm{~L}{ }^{-1}\right)$ instead of $\mathrm{pH}=1$, the intensity of the $250 \mathrm{~cm}^{-1}$ band is considerably lower. However, by decreasing the $\mathrm{pH}$ of the electrolyte by addition 5 of perchloric acid, the intensity of the $250 \mathrm{~cm}^{-1}$ band rises again, the intensity of this band at $250 \mathrm{~cm}^{-1}$ therefore depends on the $\mathrm{pH}$.

Finally, this band is close to the main one of $\gamma$-FeOOH $\left(250 \mathrm{~cm}^{-1}\right)$ and is characteristic of the surface of particles present on gold (as enhancement due to SERS effect is much more effective near the electrode surface), thus we can assume that it represents the hydrolyzed part of $\gamma-\mathrm{Fe}_{2} \mathrm{O}_{3}$ when surrounding medium is acidic. This is consistent with AFM measurements which do not indicate

10 any significant change in the size distribution of the particles deposited onto gold in acidic medium (see Figure 1), compared with the distribution determined on mica ${ }^{12,19}$.
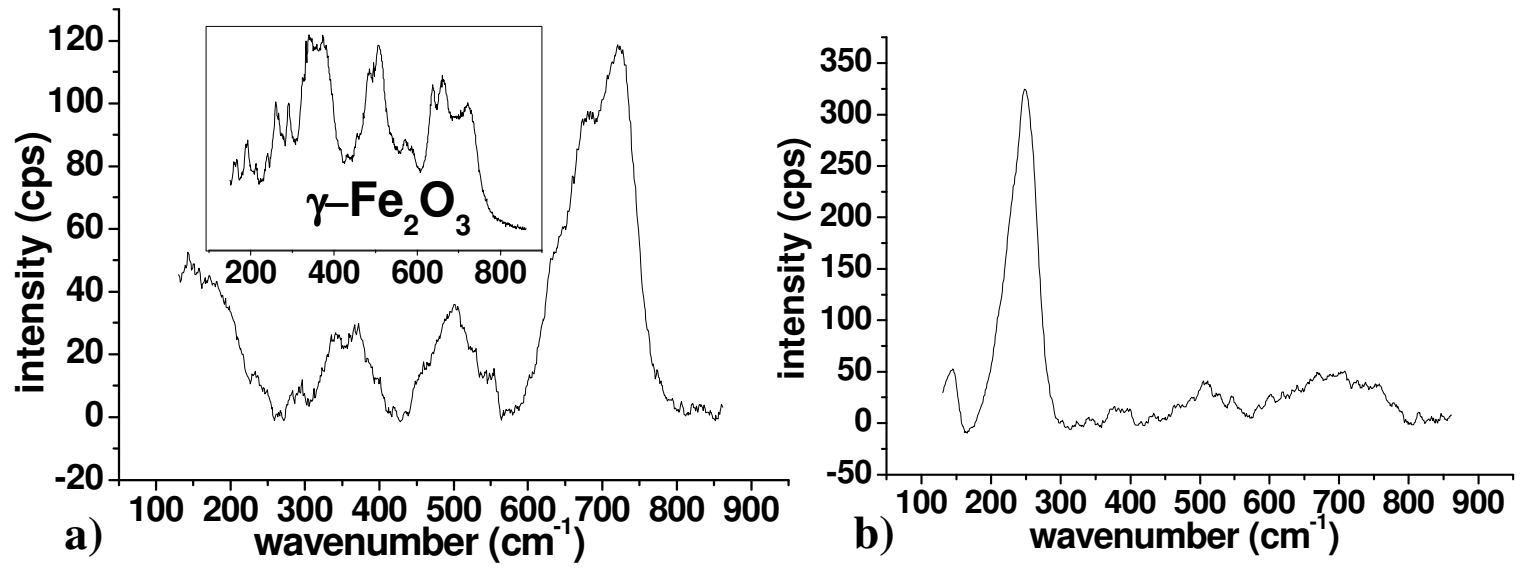

Figure 2: a) Raman spectroscopy performed in the colloidal suspension $(\mathrm{pH}=1.65, \Phi \mathrm{vol}(\%)=1.65)$, the inset shows a spectrum of bulk maghemite as reference. b) Raman spectroscopy performed on a gold electrode with iron oxides particles deposited on its surface, 15 covered with $\mathrm{HClO}_{4}$ at $\mathrm{pH}=3$.

\section{b) Electrochemical transformations}

After deposition of the particles onto gold and subsequent rinsing (see $\$ 2.3$ ), the cyclic voltammetric measurements are performed 20 in $\mathrm{HClO}_{4}$ at $\mathrm{pH}=3$. Under such conditions, the domain of electroactivity of gold is large $[-1.8 \mathrm{~V} ;+1.0 \mathrm{~V}]$, and thanks to the high conductivity of $\mathrm{H}^{+}\left(34.9 \mathrm{~S} \mathrm{~m}^{-1}\right)$, the conductivity of the electrolyte remains high although its concentration $\left(10^{-3}\right.$ mol $\left.\mathrm{L}^{-1}\right)$ is considerably lower than usual supporting electrolytes $\left(0.1 \mathrm{~mol} \mathrm{~L}^{-1}\right)$. Figure 3 shows two voltammograms measured in $\mathrm{HClO}_{4} \mathrm{pH}=$ 3 , before and after deposition of the particles. The electrode is polarized between $-1.8 \mathrm{~V}$ and $+1.0 \mathrm{~V}$, and the ramp in potential starts from $+0.05 \mathrm{~V}$ (near the open circuit potential at $\mathrm{pH}=3^{12}$ ) toward negative values. 


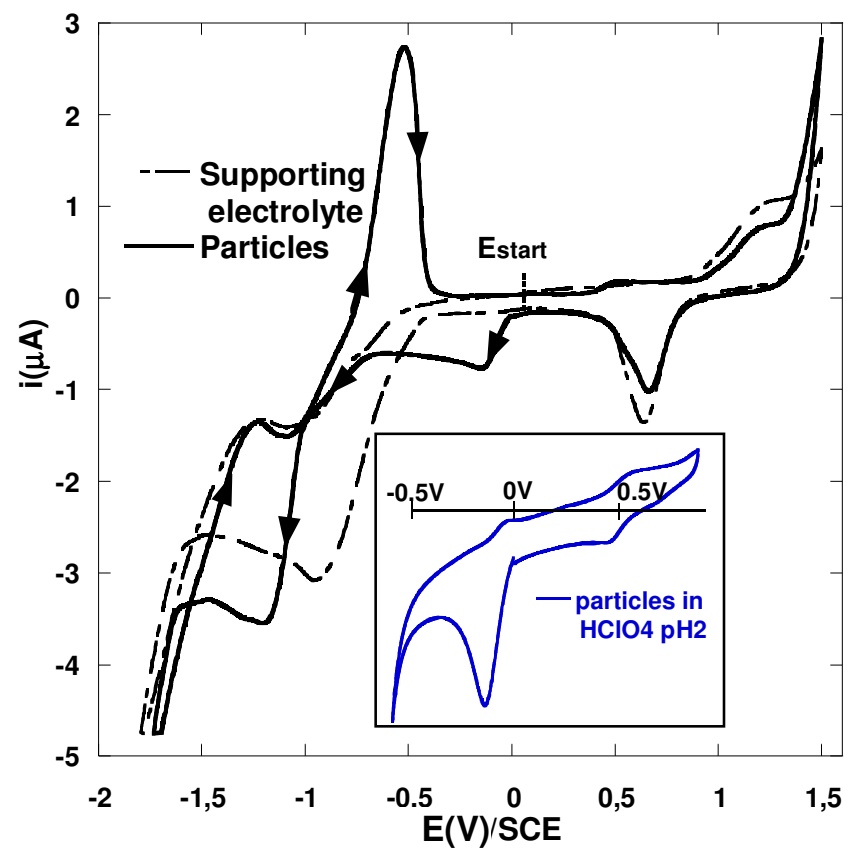

Figure 3: Cyclic voltammetry performed on a polycrystalline gold electrode. The potential scan is performed from $+0.05 \mathrm{~V}$ toward negative values. (Scan rate: $100 \mathrm{mV} / \mathrm{s}, \mathrm{E}(\mathrm{V})$ vs SCE). Dashed line: supporting electrolyte, full line: the electrode is dipped into the colloidal suspension $\left(\mathrm{pH}=1, \Phi_{\mathrm{vol}}(\%)=0.5\right)$ during 5 minutes and then rinsed prior to cycle in $\mathrm{HClO}_{4} \mathrm{pH}=3$ and in $\mathrm{HClO}_{4}$ at $\mathrm{pH}=2$ 5 (see the Inset).

Let us look first at the voltammogram in pure electrolyte, when there are no adsorbed particles at the surface of gold. Oxidation and reduction peaks appear in the positive potential range $[+0.6 \mathrm{~V} ;+1.5 \mathrm{~V}]$ just before the oxygen evolution. Those peaks correspond to the formation of oxides at the surface of the gold electrode that are subsequently reduced when the potential ramp is reversed. While increasing the $\mathrm{pH}$, the oxidation peak is shifted toward lower potentials and its intensity is higher than at lower ${ }_{10} \mathrm{pH}$. To avoid the occurrence of these oxides, the potential scan can be restricted to less than $+1 \mathrm{~V}$ at $\mathrm{pH}=3$. In the cathodic domain, the peaks occurring at $-0.8 \mathrm{~V}$ and $-1.7 \mathrm{~V}$ correspond to the reduction of the free protons in solution and to the electroactive domain limit (hydrogen evolution) respectively.

Once particles are adsorbed onto the electrode, the voltammogram obtained presents many changes. While decreasing potential from $+0.05 \mathrm{~V}$, a first reduction peak occurs at $-0.2 \mathrm{~V}$ associated to a reversible peak at $+0.5 \mathrm{~V}$, the latter being easily 15 distinguishable at $\mathrm{pH}=2$ (see the inset). At more negative potential, just before the hydrogen evolution at $-1.8 \mathrm{~V}$, a reduction peak appears at $-1.2 \mathrm{~V}$. When the potential ramp reverses from $-1.8 \mathrm{~V}$ toward positive potentials, a high oxidation peak occurs at $0.6 \mathrm{~V}$, and the peaks related to the oxidation of gold appear at the end of the first cycle. We shall now examine each peak in detail and compare the voltammograms obtained with particles (Figure 3, Figure 4b andFigure 5a) with the voltammograms obtained with ferrous ions (Figure 5b).

20 Reduction of the free protons: $E=-0.7 \mathrm{~V}$

The voltammogram performed in the supporting electrolyte without any particles adsorbed at the surface of the gold electrode exhibits a peak around $-0.7 \mathrm{~V}$ that corresponds to the reduction of the free protons in solution. Note that this peak is also observed in a solution of ferrous ions around $-0.7 \mathrm{~V}$ (Figure $5 \mathrm{~b}$ ). However, this peak is no longer observed in pure electrolyte when the particles cover the electrode (Figure 3, Figure 5a). Indeed, after deposition of the particles, the peak only appears while ${ }_{25}$ performing the second scan in potential (second cycle), not during the first cycle. Since the maghemite particles fully cover the gold surface when deposited at $\mathrm{pH}=1^{12}$, it could mean either that the reduction of $\mathrm{H}^{+}$ions is masked by the nanoparticles adsorbed on the surface of the electrode but becomes accessible again after their transformation or that the $\mathrm{H}^{+}$ions are involved in the transformation process of the particles.

Dissolution of the particles: $E=-0.2 \mathrm{~V}$

30 An ultra flat gold electrode fully covered with particles is polarized at $-0.2 \mathrm{~V}$ during 5 minutes before observation by AFM. On Figure $4 \mathrm{a}$, the observation reveals that almost no particle subsists at the surface of the electrode except a few big aggregates. Moreover, Raman spectroscopy shows that, at $-0.2 \mathrm{~V}$, the intensity of the band at $250 \mathrm{~cm}^{-1}$ decreases with time and that no new band appears. Finally at $\mathrm{pH}=3$, the intensity of the reduction peak at $-0.2 \mathrm{~V}$ progressively decreases after several cycles in the range $(-0.3 \mathrm{~V} ;+0.9 \mathrm{~V})$. Either a dissolution phenomenon of the particles during the polarization of the electrode at $-0.2 \mathrm{~V}$ or a 35 desorption of the particles once transformed could explain this result. Complementary electrochemical measurements are performed in $\mathrm{HClO}_{4}$ at $\mathrm{pH}=2$ to answer to this question.

In the inset in Figure 3, a voltammogram performed at $\mathrm{pH}=2$ shows that the peak at $\mathrm{E}=-0.2 \mathrm{~V}$ is associated to the production of the couple of peaks ("reversible peak") appearing around $+0.5 \mathrm{~V}$. These peaks, also observed with ferrous ions in $\mathrm{HClO}_{4} \mathrm{pH}^{2} 3$ 
(Figure 5b), correspond to the couple $\mathrm{Fe}^{3+} / \mathrm{Fe}^{2+}$ expected at $\mathrm{E}=+0.5 \mathrm{~V} / \mathrm{SCE}$, that is to say $\mathrm{E}=+0.75 \mathrm{~V} / \mathrm{ENH}$. Moreover the intensity of the peak at $-0.2 \mathrm{~V}$ is higher at $\mathrm{pH}=2$ than at $\mathrm{pH}=3$ (note that no effect of the addition of salt to the supporting electrolyte has been observed on the intensity of this peak) and this peak no longer appears during the second cycle. These results show that the nanoparticles are dissolved at $\mathrm{E}=-0.2 \mathrm{~V}$ and that this dissolution phenomenon is more pronounced when the $\mathrm{pH}$ 5 decreases.

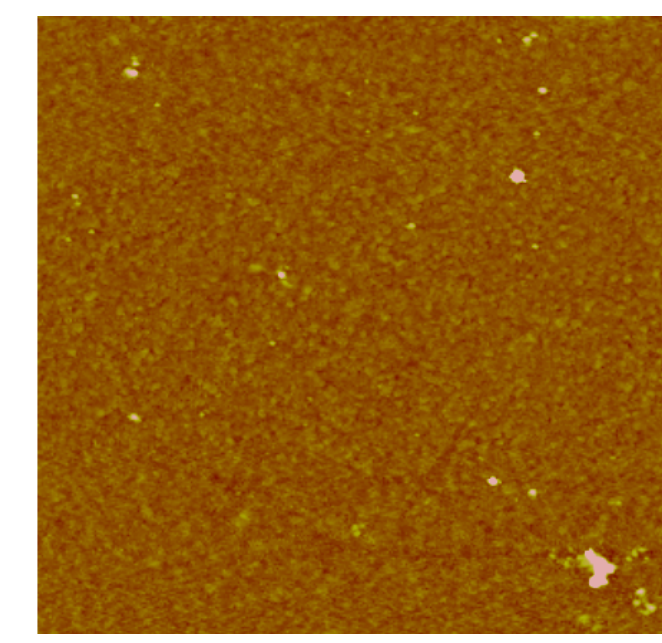

a)

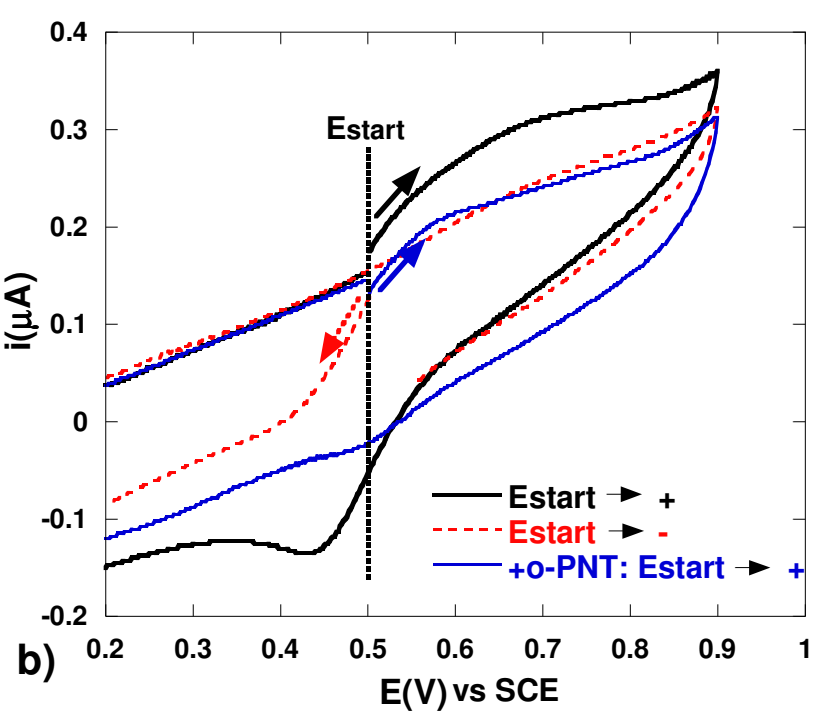

Figure 4: a) Effet of the polarisation at - $0.2 \mathrm{~V}$ : image AFM $(3 \mu \mathrm{m} \times 3 \mu \mathrm{m})$ of an ultra flat gold surface after deposition of particles $\left(30 \mathrm{~s}, \Phi_{\mathrm{vol}}(\%)=10^{-3}, \mathrm{pH}=3\right)$ and polarisation 5 minutes at $-0.2 \mathrm{~V}$ in $\mathrm{HClO}_{4} \mathrm{pH}=3$. b) Influence of the potential ${ }_{10}$ Scan (increasing: + or decreasing: -) on the reversible peak around $0.5 \mathrm{~V}$ in $\mathrm{HClO}_{4} \mathrm{pH}=2$ with or without orthophenantroline (o-PNT) after deposition of particles $\left(300 \mathrm{~s}, \Phi_{\mathrm{vol}}(\%)=0.5, \mathrm{pH}=1\right)$, scan rate $100 \mathrm{mV} / \mathrm{s}, \mathrm{E}(\mathrm{V})$ vs SCE.

In order to distinguish between the two ionic species $\mathrm{Fe}^{2+}$ and $\mathrm{Fe}^{3+}$ that can be obtained, we probe the influence of the range of potential scanned and of the presence of ortho-phenantrolin (o-PNT), a complexing agent of ferrous ions (Figure 4b).

15 After deposition of particles, the gold electrode is polarized at $-0.2 \mathrm{~V}$ just prior to scan the potential from $\mathrm{E}_{\text {start }}=0.5 \mathrm{~V}$ in the interval $[0 ; 0.9 \mathrm{~V} / \mathrm{SCE}]$. The reversible peaks appear when a positive ramp of potential is applied whereas no peak occurs when the ramp is negative. Moreover, no peak subsists after the addition of o-PNT, which means that the ferrous ions are complexed and no longer oxidized.

Hence we conclude that the particles are dissolved by reduction exclusively into ferrous ions according to the global reaction (1)

${ }_{20} \mathrm{\gamma}-\mathrm{Fe}_{2} \mathrm{O}_{3}+6 \mathrm{H}^{+}+4 \bar{e}=2 \mathrm{Fe}^{2+}+3 \mathrm{H}_{2} \mathrm{O}$

The formation of iron $\mathrm{Fe}(0)$ being expected when a highly negative polarization is applied, we will probe in the following if this dissolution phenomenon still occurs.

Reduction peaks at $-1.2 \mathrm{~V}$, at $-1.5 \mathrm{~V}$ and oxidation one at $-0.6 \mathrm{~V}: \mathrm{Fe}_{3} \mathrm{O}_{4}, \mathrm{Fe}(\mathrm{O})$ and $\mathrm{Fe}^{2+}$

In order to understand the successive steps in the electrochemical transformation of the particles and to establish the links 25 between the different peaks, we probe the influence of both the potential range scanned and of the starting potential applied before cycling. Some of these experiments are plotted in Figure 5a and are compared with the ones obtained for ferrous ions (Figure 5b). Moreover, Raman analysis versus potential and AFM measurements are performed.

When the most negative potential of the scan range is above $-1 \mathrm{~V}$, no reoxidation is observed around $-0.6 \mathrm{~V}$, both for ions and nanoparticles. However this reoxydation is observed if the more negative potential is less than $-1 \mathrm{~V}$. The reoxidation is thus linked 30 to the reduction peak around $-1.2 \mathrm{~V}$. Along this cyclic voltammetry, Raman spectra exhibit a band associated to the spinel structure of magnetite $\left(\mathrm{Fe}_{3} \mathrm{O}_{4}\right)$ that occurs at $\mathrm{E}=-1 \mathrm{~V}$, whereas below $\mathrm{E}=-1 \mathrm{~V}$, the spinel structure disappears. This last step may correspond to the transformation from magnetite or ferrous ion $\mathrm{Fe}^{2+}$ to metallic iron $\mathrm{Fe}(0)$. This simultaneous or successive reduction into $\mathrm{Fe}^{2+}$ ions and $\mathrm{Fe}(0)$ in the nanoparticles at potentials lower than $-1.2 \mathrm{~V}$ implies a loss of oxygen atoms from the structure of the particle that could affect its size.

${ }_{35}$ During the reoxidation at $-0.6 \mathrm{~V}$, no band occurs on the Raman spectra. The nature of such an oxidative transformation involving metallic iron is the preoccupation of numerous works ${ }^{23,24,13}$. These works deal with the understanding of the corrosion and of the passivation phenomenon of iron layer depending on the $\mathrm{pH}$ of the surrounding electrolyte. However, the case of nanoparticles is different as no continuous film exist, therefore no passive layer is expected to form, all the more since the thickness of Fe(0) is small (not enough $\mathrm{Fe}(0)$ is available). For nanoparticles, the oxidation step at $\mathrm{pH}=3$ may thus correspond to the dissolution of the 40 metallic iron in ferrous ion. 

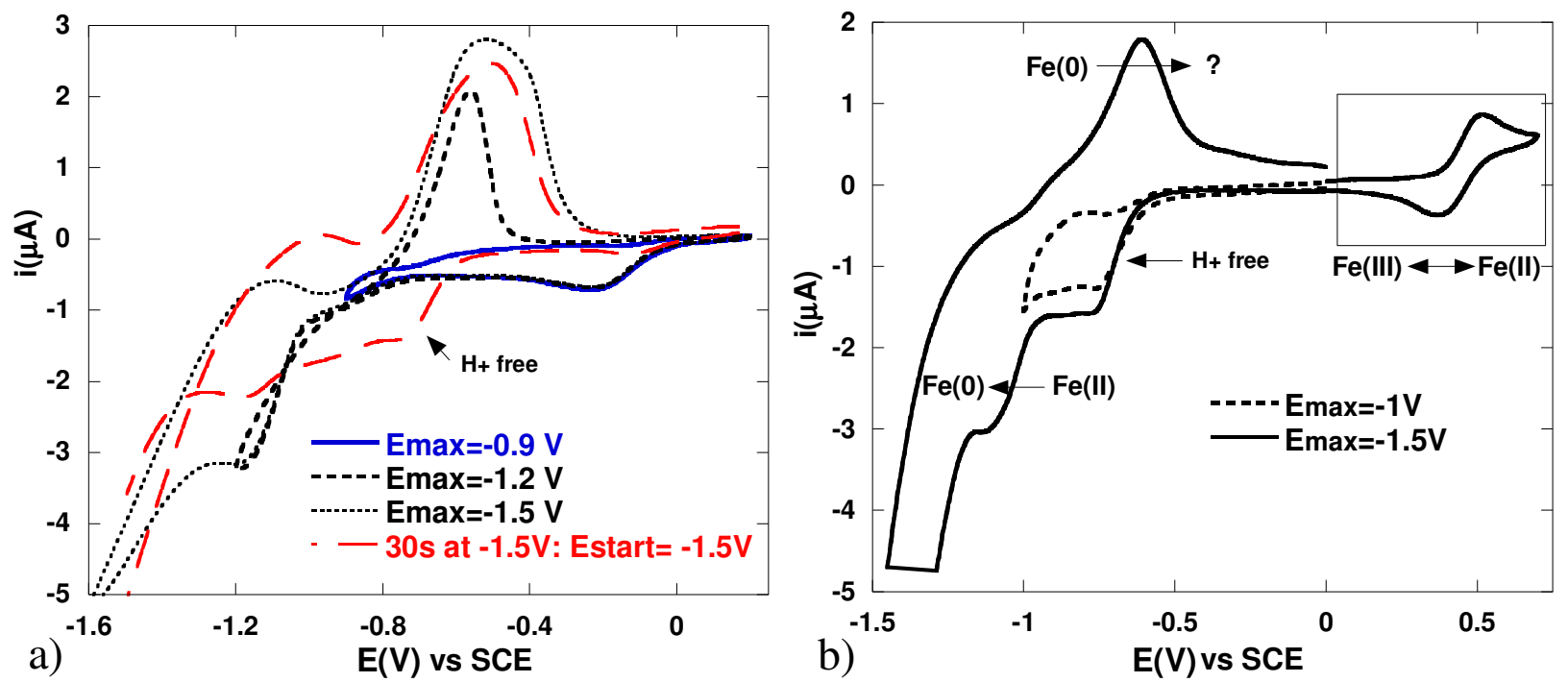

Figure 5: Cyclic voltammetry performed on a polycrystalline $\mathrm{Au}$ electrode in $\mathrm{HClO}_{4}$ at $\mathrm{pH}=3$ as a supporting electrolyte (scan rate 100 $\mathrm{mV} / \mathrm{s}, \mathrm{E}(\mathrm{V}) / \mathrm{SCE})$. a) particles are adsorbed at the surface of the gold electrode: the potential is scanned from $+0.2 \mathrm{~V}$ to $\mathrm{E}=-0.9,-1.2,-$ $51.5 \mathrm{~V} / \mathrm{SCE}$ and from $-1.5 \mathrm{~V}$ toward positive potentials after a polarization at $-1.5 \mathrm{~V}$ during $30 \mathrm{~s}$ b) ferrous ions $\left(610^{-4} \mathrm{~mol} \mathrm{~L}^{-1}\right)$ in $\mathrm{HClO}_{4}$ $\mathrm{pH}=3$ : the potential is scanned from $0 \mathrm{~V}$ to $\mathrm{E}=-1 \mathrm{~V}$ and $-1.5 \mathrm{~V}$.

Nanoreactor properties in acidic medium?

The influence on the size of the particles on the electrochemical transformations at highly negative potentials is probed by AFM 10 measurements, performed on gold substrate after polarization during 300s at $-1.7 \mathrm{~V}$ (see Figure 6). The analysis of the images shows a change in the size distribution of the nanoparticles compared with the initial deposit performed at the OCP: the number of particles adsorbed at the surface decreases (from 200 to $100 \mu \mathrm{m}^{-2}$ ) and the size distribution is shifted toward lower values (mean diameter: $7 \mathrm{~nm}$ ). Similar effects on the size distribution and on the number of particles adsorbed are observed when the substrate is polarized during $150 \mathrm{~s}$ at $-1.5 \mathrm{~V}$ and subsequently $150 \mathrm{~s}$ at $-0.6 \mathrm{~V}$. As a consequence, the main modification of the size of the 15 particle is not related to the reoxidation of the iron particles at $-0.6 \mathrm{~V}$ but to the reduction which occurs at $-1.7 \mathrm{~V}$.

In summary, in acidic medium, the properties of the particles, while adsorbed onto gold, are considerably modified: they are hydrolyzed (at least superficially) and are dissolved when the gold surface is polarized negatively. Even at more negative potential, the particles are successively reduced into magnetite and then into iron with an important modification of their size. However, it is difficult to conclude whether if the modification concerns the surface only or the whole volume of the particles. 20 Nevertheless, total or partial dissolution occurs whatever the potential applied if transformations occurs $(\mathrm{E}<0.2 \mathrm{~V})$ which proves that iron oxide nanoparticles do not behave in these conditions as nanoreactors during the electrochemical conversion process.

As the importance of the hydrolysis and of the dissolution phenomena depends on the $\mathrm{pH}$ of the electrolyte, they may vanish in alkaline medium. 

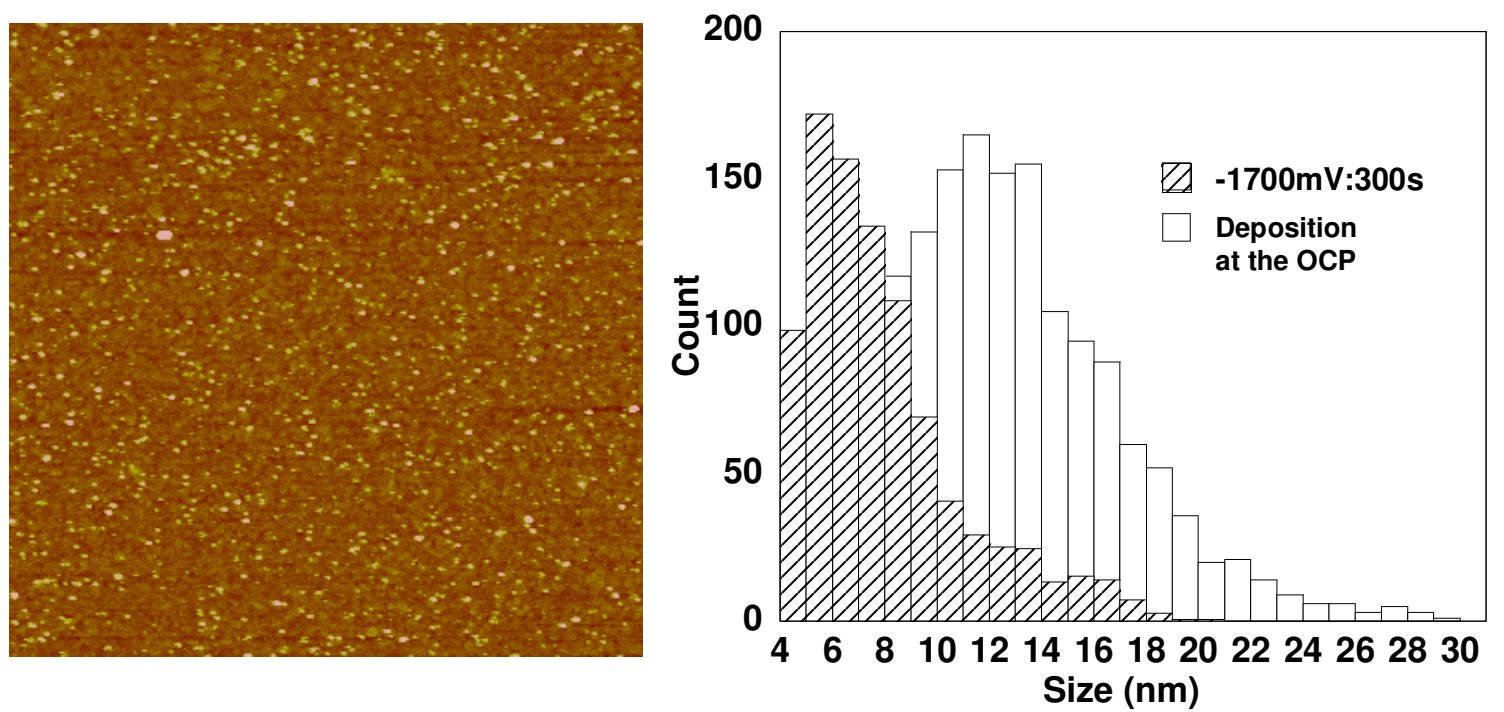

Figure 6: (Left) Image AFM $3 \mu \mathrm{m}$ x $3 \mu \mathrm{m}$ performed in oscillating mode on a gold surface after the gold substrate covered with particles (deposition at the OCP: 200 particles $\mu \mathrm{m}^{-2}$ ) has been polarized $300 \mathrm{~s}$ at $-1.7 \mathrm{~V}(\mathrm{vs} \mathrm{Ag} / \mathrm{AgCl})$ in $\mathrm{HClO}_{4}$ at $\mathrm{pH}=3$. (Right) size distribution of the particles before and after polarization.

\subsubsection{Alkaline medium}

Similar experiments are conducted in alkaline medium, however since particles do not adsorb onto the gold surface even at high ionic strength, the deposition step is realized in acidic medium. After rinsing of the gold substrate in $\mathrm{HClO} 4$ at $\mathrm{pH}=3$, voltammetry is then performed in $\mathrm{TMAOH}$ at $\mathrm{pH}=11$ and coupled to Raman spectroscopy in situ (results presented in Figure 7a).

10 To avoid the occurrence of the gold oxides, the potential scan is kept lower than $+0.4 \mathrm{~V}$ at $\mathrm{pH}=11$.

The first question is the influence of the hydrolysis phenomenon that appears in acidic medium. Indeed, the successive steps consisting in a deposition of particles in acidic condition followed by alkalinisation of the medium are not equivalent to a direct deposition of particles in alkaline conditions. With the substrate prepared in acidic medium, the Raman spectra in alkaline medium at the OCP show the band at $250 \mathrm{~cm}-1$, which corresponds to hydrolized particles (see $\S 3.3 .1 \mathrm{a}$ ). However, when the 15 potential scan starts from $0 \mathrm{~V}$ toward negative values, a band ascribed to maghemite appears on Raman spectra (see spectrum c) around $-0.5 \mathrm{~V}$ and becomes more and more pronounced at lower potentials, thus the hydrolysis process observed in acidic medium appears reversible. Note that no peak of reductive dissolution appears around $-0.2 \mathrm{~V}$ as in acidic medium.

At lower potential $(-0.8 \mathrm{~V})$ a smooth reduction peak appears followed by a reduction peak around $-1.3 \mathrm{~V}$ before the cathodic limit of the domain (decomposition of TMAOH at $-1.45 \mathrm{~V}$ ). Raman spectroscopy indicates that, at $-1 \mathrm{~V}$, magnetite is formed, as in 20 acidic medium. At a potential of $-1.2 \mathrm{~V}$, the peak of magnetite becomes well defined (spectrum c). Below $-1.2 \mathrm{~V}$, the magnetite band at $670 \mathrm{~cm}-1$ disappears concomitantly with the cathodic peak at $-1.3 \mathrm{~V}$ in the voltammogram, however a large band of low intensity (from 400 to $1000 \mathrm{~cm}-1$, see spectrum d) remains, which could be related to a thin layer of oxides at the surfaces of the iron particles or at the surface of the gold electrode.

When the potential scan reverses, a few successive small oxidation peaks between $-1 \mathrm{~V}$ and $-0.2 \mathrm{~V}$ appears on the voltammogram, ${ }_{25}$ which are however different from those produced in acidic medium. The intensity of these peaks remains constant during the following cycles and could concern the electrochemical conversion of only a fine oxide layer as already explained above, if no dissolution phenomenon occurs. 

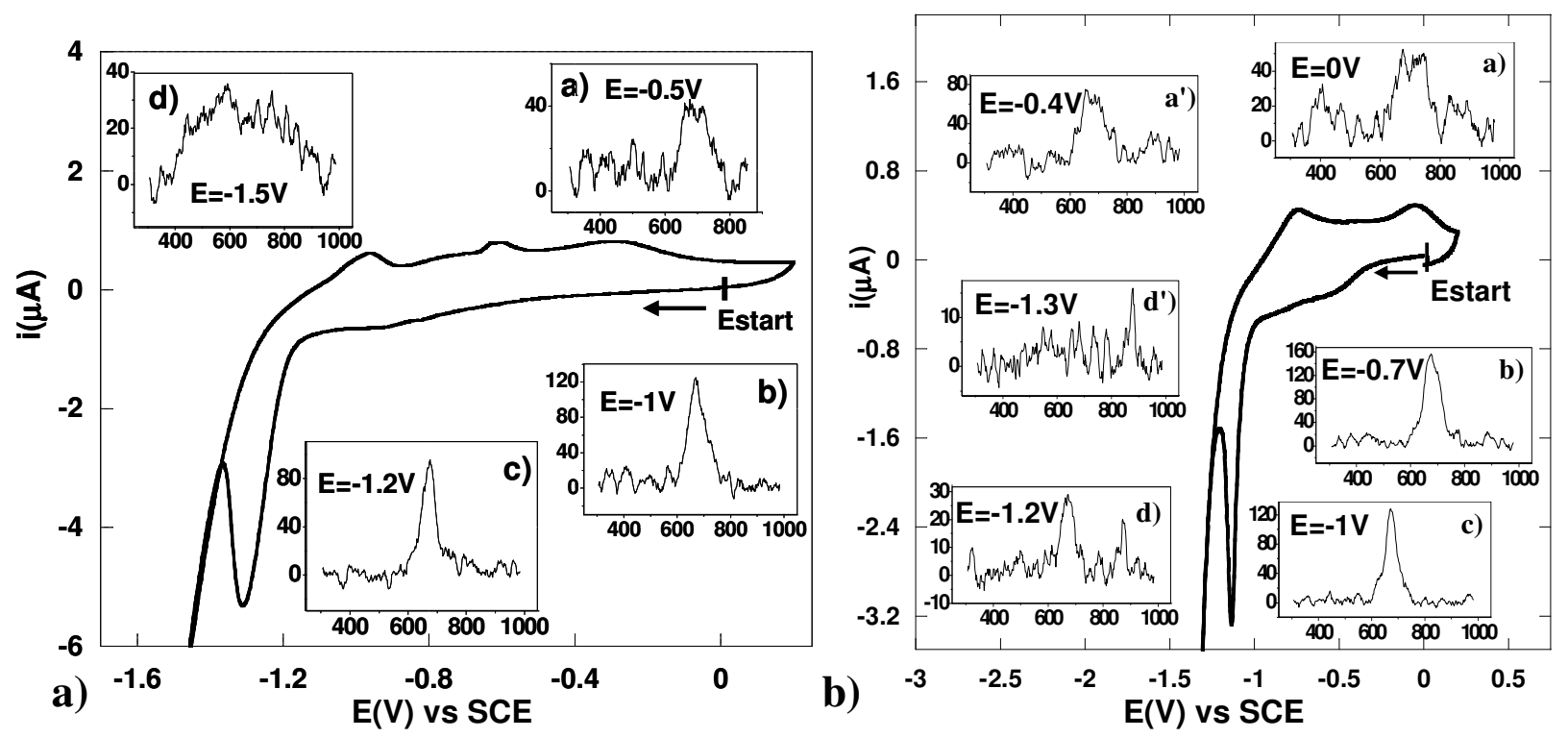

Figure 7: Cyclic voltammetry performed on a polycrystalline electrode a) in TMAOH at $\mathrm{pH}=11$ and $\mathbf{b}$ ) in borate buffer solution at $\mathrm{pH}$ $=8.4$ as supporting electrolyte. The potential is scanned from $0 \mathrm{~V}$ toward negative values. (Scan rate: $100 \mathrm{mV} / \mathrm{s}, \mathrm{E}(\mathrm{V}) \mathrm{vs} \mathrm{SCE}$ ). The electrode is dipped during 5 minutes in the colloidal suspension $(0.5 \%, \mathrm{pH}=1$,) and then rinsed prior to cycle (full line). Insets: Raman 5 spectra (intensity in cps as a function of the wave number $\mathrm{cm}^{-1}$ indicated on each spectrum) at different potentials applied at the gold electrode.

The same experiments are performed in another medium in order to probe the influence of the nature of the ions of the electrolyte. A borate buffer solution at $\mathrm{pH}=8.4$ is chosen because it is commonly applied to study the formation of iron passive film ${ }^{3}, 23,24$.

10 The spectra recorded exhibit similar peaks (maghemite, magnetite, see Figure $7 \mathrm{~b}$ ), but the spectra ( $\mathrm{d}$ and $\mathrm{d}$ ') associated to the last reduction step do not exhibit any large band as observed in alkaline medium, but only a few peaks of low intensity. Note that the absence of the peak can not be ascribed to dissolution of the particle into ions because, at this $\mathrm{pH}$, the ions would be precipitated in oxide form, and would probably be detected in Raman spectroscopy. This means that metallic iron is formed, however it is not possible to assert that this transformation affects the whole volume of the particle. Finally, these experiments also show that there 15 is a weak influence of the nature of the ions of the electrolyte, the pH being the most influential parameter.

As already performed in acidic medium, AFM measurements are performed on the gold surface with adsorbed particles, previously polarized at $-1.7 \mathrm{~V}$ in $\mathrm{TMAOH} \mathrm{pH}=11$ during 5 minutes, in order to probe a possible change of the size of the particles. The Figure 8 shows the structure of the deposit (AFM image $1 \mu \mathrm{m} * 1 \mu \mathrm{m}$ ), a cross section of this image shows objects in the $10 \mathrm{~nm}$ size range. The statistical distribution of the size of the particles after their electrochemical transformation realized on 202000 particles is in good agreement with the size distribution of the particles deposited at the OCP (Figure 2), which means that there is no modification of size. Note that, if the particles are transformed into metallic iron, their size decreases, but the metallic iron is oxidized during the drying and intermediate steps before AFM measurements. Therefore, the particles observed with AFM are expected to have the same size as the initial particles if they behave as a nanoreactor. We can conclude that the particles behave as nanoreactor under the conditions used here in alkaline medium, however, since the SERS effect in Raman spectroscopy 25 appears at the surface of the particle, we are not sure that the whole particle is transformed. 

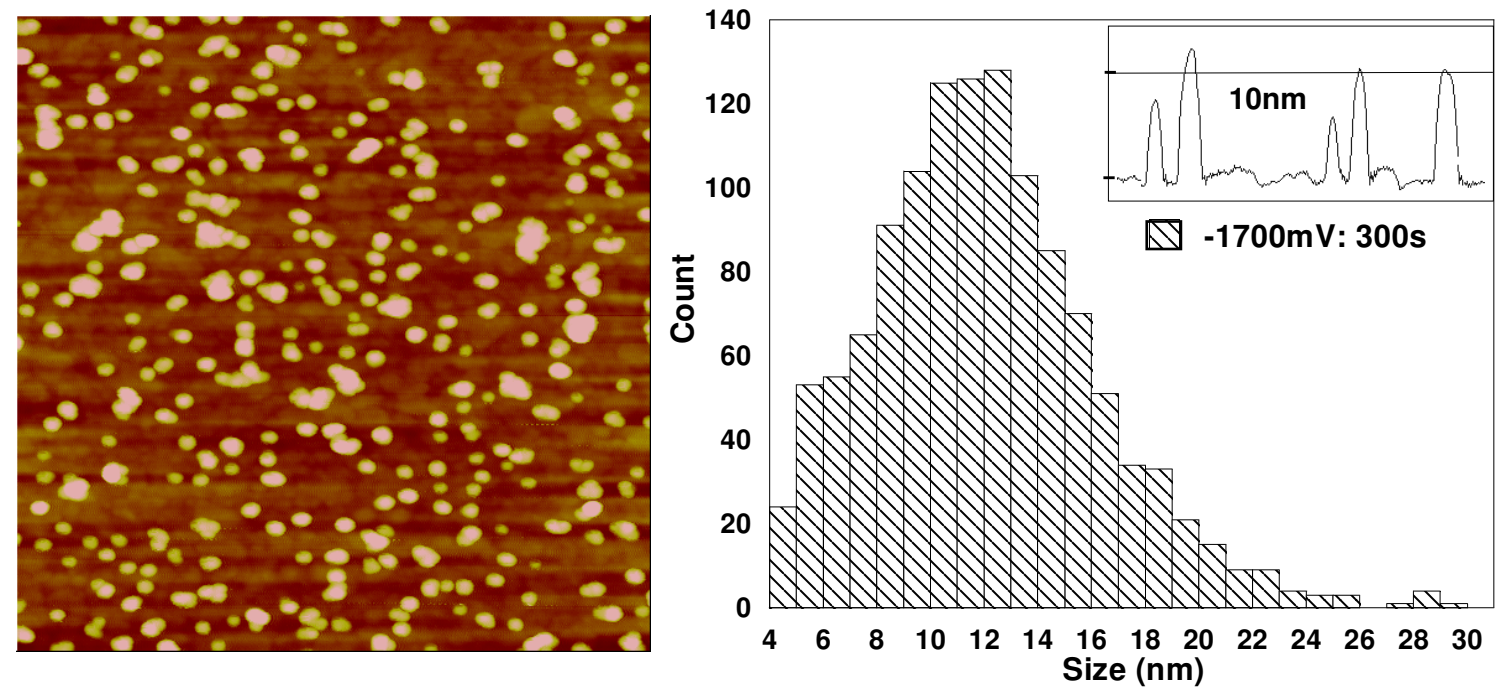

Figure 8: AFM picture $1 \mu \mathrm{m} \times 1 \mu \mathrm{m}$ of iron oxide nanoparticles adsorbed onto a gold surface (mean roughness $<0.5 \mathrm{~nm}$; 200 particles $\mu \mathrm{m}^{-2}$ ) after polarization of the substrate at $-1.7 \mathrm{~V}(\mathrm{vs} \mathrm{Ag} / \mathrm{AgCl})$, and the size distribution of the particle adsorbed. The inset represents a cross section of the AFM image.

\subsection{Probing of the "nanoreactor" properties of the particles at a mercury electrode}

Using the conclusions obtained on gold, the same kind of experiments are now performed on mercury, the advantage of which is the possibility to prepare a sufficient amount of particles dispersed into mercury after a preparative experiment in order to analyze the properties of the resulting material. From this, we expect to access to complementary information not accessible from the previous experiments.

${ }_{10}$ Since the size of the particles appears to be conserved after the electrochemical reduction at a gold electrode under alkaline conditions, this medium is chosen to probe the nanoreactor properties of the particles at a mercury electrode. Analytical electrochemical measurements similar to those performed previously on gold, i.e. separating the adsorption and the reaction steps, are performed first on the mercury drop and compared to the previous results. Then, preparative experiments are also performed in order to answer to the following questions: does the transformation affect the whole volume of the particle and is the size of the

15 initial particle maintained during preparation? A direct analysis of the particle size in this material using AFM after evaporation of the mercury has been attempted, however this procedure was not successful, probably due to incomplete evaporation of the mercury (leaving nanometric objects on the mica surface) and/or modification of the sample during the evaporation process at high temperature. The resulting material was then analyzed using magnetic measurements as a function of temperature. With this technique, the property of nanoreactor of the particle is probed by comparing the results of three electrolyses with nanoparticles of 20 three different mean sizes.

Analytical voltammetry at the mercury electrode

For the analytical study on mercury, we separate the deposition process and the electrochemical measurements as done with the gold electrode. The deposition is realized by using the hanging mercury drop in a colloidal suspension $(\square \operatorname{vol}(\%)=0.5)$ at $\mathrm{pH}=$ 13, which corresponds to a high ionic strength and allows the particles to approach to the mercury surface whatever the potential 25 applied. In these conditions, the saturation of the mercury surface is reached after 5 minutes. Then, the mercury drop is rinsed carefully and plunged into the supporting electrolyte (TMAOH, 10-3 mol L-1). The potential scan starts from $0 \mathrm{~V}$ toward negative values. The voltammogram in Figure 9a shows several reduction peaks: a broad peak between $-0.9 \mathrm{~V}$ and $-1.2 \mathrm{~V}$ (vs $\mathrm{Ag} / \mathrm{AgCl}$ ), and a sharp peak at $-1.6 \mathrm{~V}$ before the cathodic limit of the electroactive domain (TMAOH decomposition) at $-1.9 \mathrm{~V}$. The reoxydation around $-0.7 \mathrm{~V}$ is linked to the broad peaks around $-1 \mathrm{~V}$. By comparison with gold, these latter peaks probably 30 correspond to a partial reduction of the particles, and the sharp peak close to the limit of the electroactivity domain is expected to correspond to the formation of metallic iron. 

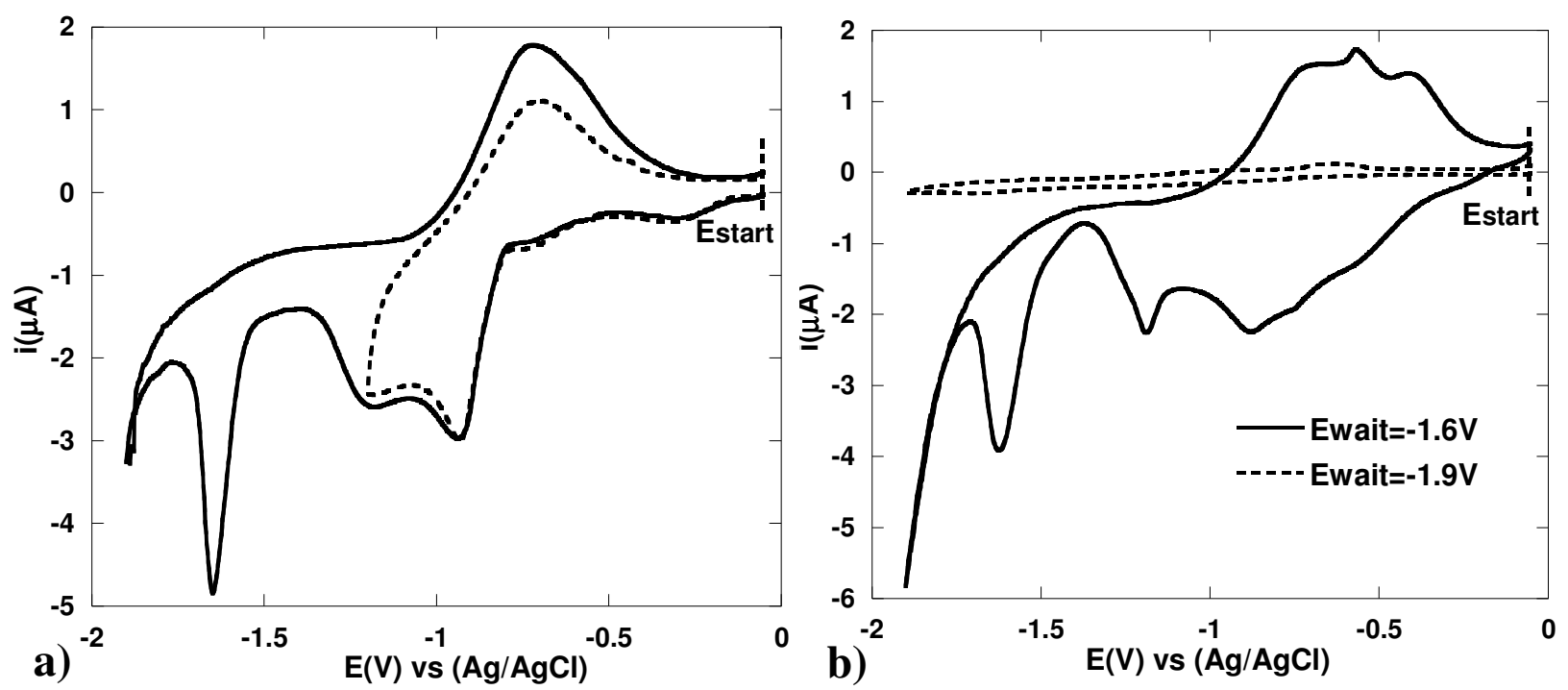

Figure 9: Voltammograms performed at a hanging mercury drop electrode in TMAOH, $10^{-3} \mathrm{~mol} \mathrm{~L}^{-1}$ : The electrode is previously plunged into a colloidal suspension $\left(\Phi_{\mathrm{vol}}(\%)=0.5\right)$ in TMAOH $\mathrm{pH}=13$ during 5 minutes. Scan rate: $\left.100 \mathrm{mV} / \mathrm{s}, \mathrm{E}(\mathrm{V}) \mathrm{vs} \mathrm{Ag} / \mathrm{AgCl}\right)$. a) $\mathrm{The} \mathrm{scan}$ starts from $-0.05 \mathrm{~V}$ toward negative values. b) Before scanning from $-0.05 \mathrm{~V}$, the electrode is maintained at fixed potential ( $-1.6 \mathrm{~V}$ or $51.9 \mathrm{~V}$ ) during $30 \mathrm{~s}$.

In Figure $9 \mathrm{~b}$ is shown the influence of a prepolarization of the mercury drop covered by nanoparticles. The electrode is polarized at extreme potential values during $30 \mathrm{~s}$ in TMAOH $10^{-3} \mathrm{~mol} \mathrm{~L}^{-1}$, before scanning from $-0.05 \mathrm{~V}$ toward negative values. When prepolarized at $-1.6 \mathrm{~V}$, the shape of the voltammogram is roughly the same as in Figure 9a. On the contrary, after polarizing the 10 electrode at $-1.9 \mathrm{~V}$, the voltammogram obtained is similar to the one of the supporting electrolyte. If we consider that no desorption occurs even at extreme potential as shown on the gold electrode, it means that the particles initially adsorbed on the electrode have been transformed and are incorporated in the mercury electrode. Moreover, the voltammogram shows that no reoxidation peak is associated to the peak at $-1.6 \mathrm{~V}$, which means that the entities incorporated in mercury are not reoxidizable.

Electrolysis at the mercury electrode

15 To produce a sufficient amount of material that can be analyzed implies to switch from analytical experiments toward electrolysis, a change of scale which has several important consequences. Firstly, the mercury drop electrode is no longer used but replaced by a pool (around $1 \mathrm{~cm}^{3}$ ), the surface of which is stirred with a glass paddle which also stirs the aqueous solution. Secondly, the electrolyte is concentrated so that the $\mathrm{pH}$ does not change during the reaction ([TMAOH] $=0.2$ mol.L $\mathrm{L}^{-1}$ ). Note that the colloidal suspensions studied here remain stable at this concentration of TMAOH. At this concentration, the particles approach the

20 electrode whatever the potential applied, however the deposition and the transformation steps are no longer separated as done during the analytical measurements. Thus, to avoid a too fast adsorption of the nanoparticles on the electrode, the electrolysis is performed with a low concentration of iron (around $2.10^{-3} \mathrm{~mol} . \mathrm{L}^{-1}$ ) and electroactive species are evenly added. These preparative electrolyses are performed using three ferrofluids characterized by different mean sizes of the particles and by reduced polydispersities (see Table 1).

\begin{tabular}{|c|c|c|c|c|c|c|}
\hline $\begin{array}{c}\text { Sample in } \\
\text { water }\end{array}$ & $\mathrm{d}_{\mathrm{o}}(\mathrm{nm})$ & $\sigma$ & $\begin{array}{c}\text { Sample in } \\
\mathrm{Hg}\end{array}$ & $\Phi_{\mathrm{vol}}(\%)$ & $\mathrm{m}_{\mathrm{s}}(\mathrm{kA} / \mathrm{m})$ & $\mathrm{T}_{\mathrm{b}}(\mathrm{K})$ \\
\hline $\mathrm{L}$ & 9.7 & 0.29 & $\mathrm{Hg}-\mathrm{L}$ & 0.095 & 1510 & 300 \\
\hline $\mathrm{M}$ & 6.6 & 0.22 & $\mathrm{Hg}-\mathrm{M}$ & 0.070 & 1440 & 200 \\
\hline $\mathrm{S}$ & 4.8 & 0.2 & $\mathrm{Hg}-\mathrm{S}$ & 0.035 & 1450 & 150 \\
\hline
\end{tabular}

Table 1: Characteristics of the samples in water used for the electrolysis: mean size $\mathrm{d}_{\mathrm{o}}$ and polydispersity $\sigma$ characteristize the lognormal distribution of the sizes of the nanoparticles determined from magnetization measurements ${ }^{17}$. Characteristics of the samples obtained in mercury: volume fraction of particles $\Phi_{\mathrm{vol}}(\%)$, magnetization of the material $\mathrm{m}_{\mathrm{s}}$ at $\mathrm{T}=300 \mathrm{~K}$, and blocking temperature $\mathrm{T}_{\mathrm{b}}$ (see text).

Given the changes of experimental conditions imposed by the electrolysis, the voltammograms performed on the mercury drop 
directly in the colloidal dispersion (Figure 10a) are first compared to those obtained previously through the two steps process (adsorption/reaction, Figure 9). It shows that similar peaks are observed in both experiments, however the broad peaks around $1 \mathrm{~V}$ (partial reduction) in Figure 10 are smaller than expected according to Figure 9a, given the height of the peak at $-1.7 \mathrm{~V}$ (metallic iron). This difference can be explained by the high variability of these peaks of partial reduction, which can be observed 5 on the different mercury electrodes. For instance on a $\mathrm{Hg}$ drop, these peaks indeed increase after repeated voltammetries on the same drop or after the drop has spent a long time in the solution ( $5 \mathrm{mn}$ to $25 \mathrm{mn}$ ). Due to the drastic change in the interface area (from the drop size to the pool size), the heights of the peaks show different dependences with the history of the electrode, which probably result from the evolution of the surface during the electrolysis. Contrary to the mercury drop, the mercury pool being a non renewed-interface, one cannot avoid the multiple and uncontrolled accumulations of foreign species contained in the 10 electrolyte (ionic as well as non-ionic) or generated, especially if it occurs at times longer than the average time of an experiment on a mercury drop. Such contamination of the interface can at least modify the effective area of the working electrode in an unpredictable extent. The differences observed between the two types of experiments could also be linked to the ratio of the working area of the electrode versus the length of the interface mercury/glass/electrolyte, this length being very small for the hanging drop and well developed around the pool. In this peculiar zone of the interface electrocapillary forces are strongly enough 15 to modify the meniscus with visible convection effects increasing the mass transfer especially at negative potential. However, the changes observed on the voltammogramms have no major effect on the potential of the final reduction step, leading anyway to the production of the magnetic fluid.

Concerning the peak at $-1.7 \mathrm{~V}$ in Figure 10a, there is a strong influence of the size of the nanoparticles on its height: the current increases with the size of the particles although all experimental conditions are identical for the three sizes (potentials, times and

20 equivalent iron concentration). Indeed, for an equivalent iron concentration, the number of small particles is higher than the one of large particles, and their diffusion coefficient is also higher, thus the current should be higher for the smaller particles within this simple analysis. The opposite result obtained thus comes either from the adsorption phenomenon or from the electrochemical transformation.

Let us now focus on the preparative electrolysis. It is necessary to define parameters which are a compromise. Indeed, adsorption 25 and reaction occur at the same time and the ratio of the number of particles adsorbed on the electrode per second to the number of particles transformed per second is crucial. It can be controlled mainly by the concentration of particles and by the potentials applied.

In a first place, note that, if the electrolysis is performed at $\mathrm{E}>-1.5 \mathrm{~V}$, the mercury obtained has no magnetic properties, which means that there is no metallic iron in the mercury. This confirms that the peak at $-1.7 \mathrm{~V}$ corresponds to the reduction to metallic 30 iron whereas the peaks around $-1 \mathrm{~V}$ correspond to partial reduction. However, if the electrolysis is performed at $\mathrm{E}<-1.5 \mathrm{~V}$, the electrolytic current decreases quickly in time as if the surface was blocked for electrochemical reactions. It is probable that the rate of conversion of the nanoparticles is too slow as compared to their rate of adsorption. As was shown in Figure $9 b$, the conversion is faster for more negative potentials. Therefore, negative potential pulses have been superimposed to the fixed potential applied. The optimisation of the parameters led to the following values: $\mathrm{E}_{\text {electrolysis }}=-1.7 \mathrm{~V}$, with negative impulsions $\Delta \mathrm{E}$ ${ }_{35}=0.65 \mathrm{~V}$ (meaning that $\mathrm{E}=-2.35 \mathrm{~V}$ ) of duration $300 \mathrm{~ms}$, every $10 \mathrm{~s}$. Under such conditions, the averaged electrolytic current is stable and slowly decreases with the concentration of electroactive species. The impulsions thus allow to accelerate the transformation. As mentioned above, nanoparticles are added when the current decreases in order to keep the iron concentration in the range $\left[10^{-2}-3.10^{-2}\right.$ mol. $\left.\mathrm{L}^{-1}\right]$ and in order to obtain a quantity of material high enough at the end of the electrolysis.

The high difference in current for the three samples is also observed during the electrolysis as previously shown in analytical 40 experiments reported in Figure 10a. Indeed, the mean current decreases while decreasing the size of the particles, which means that the electrolysis, thus the achievement of the magnetic material, is time-consuming with small particles. However, the estimation of the electrochemical yield of the electrolysis shows that the direct reaction $\mathrm{Fe}^{\mathrm{III}} \rightarrow \mathrm{Fe}^{0}$ corresponds to 30 to $50 \%$ only of the electrons consumed whatever the size. The nature and the mechanism of the transformation may very likely be similar for the three sizes (the quasi-identical potentials of the peak reduction currents being an indication, not a proof). This observation

45 thus indicates that the difference of current likely results from a difference in the adsorption phenomenon according to the particles sizes.

Analysis of the materials

After the preparative electrolysis, the materials are kept frozen at $-80{ }^{\circ} \mathrm{C}$ in order to avoid any evolution, before the analyses are performed in the following days. The amount of iron in mercury is determined, after extraction of the iron with $\mathrm{HCl} 37 \%$, by

50 flame atomic absorption spectroscopy. The magnetic measurements are performed using a SQUID (Superconducting Quantum Interference Device).

Firstly, the measurement at $\mathrm{T}=300 \mathrm{~K}$ (liquid sample) shows a magnetization curve $\mathrm{M}=\mathrm{f}(\mathrm{H})$ characteristic of a superparamagnetic sample ${ }^{17}$ : each particle is a magnetic dipole so that $\mathrm{M}$ increases with $\mathrm{H}$ and saturates when all the particles are oriented along the field. The magnetization at saturation $\mathrm{M}_{\mathrm{s}}$ is proportional to the volume fraction $\Phi_{\mathrm{vol}}$ of particles in mercury: $\mathrm{M}_{\mathrm{s}}=\mathrm{m}_{\mathrm{s}} \Phi_{\mathrm{vol}}, \mathrm{where}$ $55 \mathrm{~m}_{\mathrm{s}}$ is the magnetization of the material. Here we determine $\mathrm{m}_{\mathrm{s}}$ for the three samples (see Table 1). The value, which is around $1500 \mathrm{kA} / \mathrm{m}$, is lower than the value of $1700 \mathrm{kA} / \mathrm{m}$ for bulk metallic iron, phenomenon which is usually observed with magnetic nanoparticles as iron ${ }^{25}$. However this is much higher than the value of $300 \mathrm{kA} / \mathrm{m}$ obtained for the initial maghemite nanoparticles ${ }^{17}$, which are here electrochemically reduced. It means that the whole volume of the particles is reduced and not only 
the surface.

Secondly, $\mathrm{M}$ is measured at $\mathrm{H}=50 \mathrm{Oe}=4 \mathrm{kA} / \mathrm{m}$ as a function of the temperature from $\mathrm{T}=5 \mathrm{~K}$ to $\mathrm{T}=300 \mathrm{~K}$ for two samples prepared in different conditions: (i) in the field cooling (FC) experiment, the sample is frozen under $\mathrm{H}=50 \mathrm{Oe}=4 \mathrm{kA} / \mathrm{m}$; (ii) in the zero field cooling (ZFC) experiment, the sample is frozen under $\mathrm{H}=0$. The results are plotted in Figure 10b. The ZFC curve ${ }_{5}$ presents a maximum at a temperature $\mathrm{T}_{\mathrm{b}}$, which depends on the sample. Taking into account the low concentration of the samples and the low field value, this can be interpreted in a first approximation in the framework of the superparamagnetic blocking formalism ${ }^{17}$. The important parameter is then $E_{a} / k T$ where $E_{a}$ is the anisotropy energy of the particles. If $E_{a} / k T>>25$, the magnetic moment is blocked inside the particles and no ZFC magnetization appears under field. If $\mathrm{E}_{\mathrm{a}} / \mathrm{kT}<<25$, the magnetic moment can turn inside the particles and a ZFC magnetization is induced under field. The ZFC peak corresponds to a change from 10 one dynamical regime to the other, so that $E_{a} / k T \sim 25$. As $E_{a}$ depends on the size of the particle ${ }^{17}$, it means here that the size of the particles in mercury increases when the size of the initial particles increases.

This nicely proves that the nanoparticles can behave as nanoreactors when the conditions are appropriate, as it is the case in the alkaline medium.

15
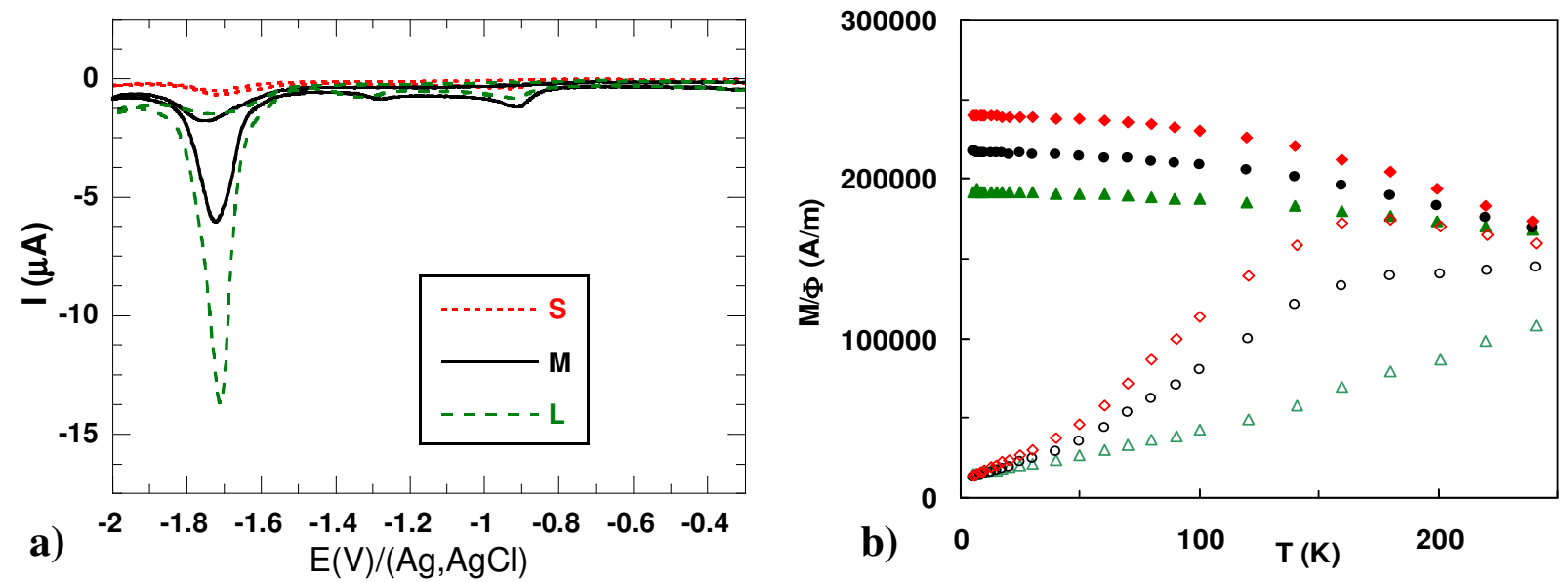

Figure 10: a) Cyclic voltammetry performed at a hanging mercury drop electrode in a colloidal suspension $\left([\mathrm{TMAOH}]=0.2 \mathrm{~mol} \mathrm{~L}^{-1}\right.$; [Iron] = $610^{-4} \mathrm{~mol} \mathrm{~L}^{-1}$; Scan rate: $100 \mathrm{mV} \cdot \mathrm{s}^{-1}$ ) with 3 sizes of particles small (S), medium (M) and large (L) (see Table 1). b) Magnetization curves as a function of the temperature and of the size of the particles: $\mathbf{S}=$ diamonds, $\mathbf{M}=\operatorname{circles}, \mathbf{L}=\operatorname{triangles}$. $\mathrm{H}=50 \mathrm{Oe}$ $20=4 \mathrm{kA} / \mathrm{m}$. Open symbols: ZFC, full symbols: FC (see text for details).

\section{Conclusion and perspectives}

In this study, we investigated the properties of iron oxide nanocolloidal particles which have undergone electrochemical modifications. We were interested in particular in the nanoreactor behaviour of the nanoparticles, that is to say the conservation of their size throughout their electrochemical transformation; this property of nanoreactor being researched in the elaboration of a 25 magnetic and conductive liquid that derives from the magnetic colloidal suspension.

For that, we probed the electrochemical behaviour of the particles, after they have adsorbed onto the electrode, as a function of the $\mathrm{pH}$ at a gold electrode. The use of complementary tools such as the atomic force microscopy and the Raman spectroscopy allowed probing both the size and the chemical nature of the objects adsorbed at the surface of the gold electrode as a function of the applied potential. Firstly, we observed in acidic medium a modification in the chemical nature of the surface of the particles 30 adsorbed at the surface of the gold electrode that is assimilated to a hydrolysis phenomenon. This phenomenon appears to be reversible in alkaline medium. Secondly, a dissolution process takes place when negative potentials are applied to the electrode that imply deep changes in the size of the particles in acidic medium whatever the potential thus whatever the final oxidation state of the iron (II or 0).

In alkaline medium and at highly negative potential, particles are electrochemically converted at a gold electrode into metallic 35 iron and the integrity of each particle is kept during this transformation which means that each one is a nanoreactor under these conditions. Therefore, we use the alkaline medium to prepare dispersions of particles into mercury by preparative electroreduction of the colloidal suspension. Magnetic measurements performed on the resulting material reveal that the particles are entirely converted into iron and that the size of the dispersed objects can be controlled by the size of the iron oxide particles before their electrochemical transformation; these results are in good agreement with those obtained on the gold electrodes.

\section{${ }_{40}$ Acknowledgements}


We thank V. Dupuis for help with the magnetization measurements.

\section{Notes and references}

${ }^{a}$ Université Pierre et Marie Curie-Paris6, Laboratoire Liquide Ionique et Interfaces Chargées, UMR CNRS 7612, case courrier 51, 4 place Jussieu, F75005 Paris 5, France.

$5{ }^{b}$ Laboratoire des Interfaces et Systèmes Electrochimiques, UPR 15 CNRS, CP 133, Université Pierre et Marie Curie, 4 place Jussieu, F-75005 Paris 5 ,

France.

*ivlucas@ccr.jussieu.fr

${ }^{1}$ A. J. Bard, L. R. Faulkner Electrochemical methods: Fundamental and Applications (snd ed), John Wiley and sons, INC. 2001.

${ }^{2}$ M. Heyrovsky and J. Jirkovsky, Langmuir, 1995, 11, 4288.

${ }^{3}$ M. Heyrovsky, J. Jirkovsky and B. R.Mueller, Langmuir, 1995, 11, 4293.

${ }^{4}$ M. Heyrovsky, J. Jirkovsky and M. Struplova-Bartackova, Langmuir, 1995, 11, 4300.

${ }^{5}$ M. Heyrovsky, J. Jirkovsky and M. Struplova-Bartackova, Langmuir, 1995, 11, 4309.

${ }^{6}$ E. M. Andrade, F. V.Molina and D.Posadas, J. Colloid Interface Sci., 1994, 165, 450.

${ }^{7}$ E. M. Andrade, F. V.Molina, G.L. J. Gordillo and D.Posadas, J. Colloid Interface Sci., 1994, 165, 259.

${ }^{8}$ M. Caselli, G. Lippolis and L.Gierst, J. Elect. Anal. Chem., 1972, 38, 451.

${ }^{9}$ P. Mulvaney, R. Cooper, F. Grieser and D. Meisel, Langmuir, 1988, 4, 1206.

${ }^{10}$ P. Mulvaney, V. Swayambunathan, F. Grieser and D. Meisel, Langmuir, 1990, 6, 555.

${ }^{11}$ P. Mulvaney, V. Swayambunathan, F. Grieser and D. Meisel, J. Phys. Chem., 1988, 92, 6732.

${ }^{12}$ I.T. Lucas, E. Dubois, J. Chevalet and S. Durand-Vidal, Reactivity of nanocolloidal particles $\gamma$-Fe2O3 at the charged interfaces: 1 -Approach to the electrode, 2007, submitted to J. Phys. Chem. Chem. Phys.

${ }^{13}$ P. Allongue and S. Joiret, Phys. Rev. B, 2005, 71, 115407.

${ }^{14}$ E. Dubois, J. Chevalet and R. Massart, J. Molec. Liq., 1999, 83, 243.

${ }^{15}$ E. Dubois and J. Chevalet, Langmuir, 2003, 19, 10892.

${ }^{16}$ R. Massart and V. Cabuil, J. Chim. Phys., 1987, 84, 967.

${ }^{17}$ Magnetic fluids and Applications Handbook, Berkovski ed., Begell House Inc. Publ., N. Y. 1996.

${ }^{18}$ R. Massart, E. Dubois, V. Cabuil and E. Hasmonay, J. Mag. Mag. Mat., 1995, 149, 1.

${ }^{19}$ I. T. Lucas, S. Durand-Vidal, E. Dubois, J. Chevalet and P.Turq, Surface charge density of maghemite nanoparticles: role of the electrostatics in the protons exchange, J. Phys. Chem. C, 2007, accepted.

${ }^{20}$ E. Dubois , V. Cabuil, F. Boué and R. Perszinski, J. Chem. Phys., 1999, 111, 7147.

${ }^{21}$ P. Wagner, M. Hegner, H.-J. Guentherodt and G. Semenza, Langmuir, 1995, 11, 3867.

${ }^{22}$ A. A. Jbarah, A. Ihle, K. Banert and R.Holze, J. Raman Spectrosc., 2006, 37, 123.

${ }^{23}$ A. J. Davenport, R. L. J. Oblonsky and M. F. Toney, J. Electrochem. Soc., 2000, 147, 2162.

${ }^{24}$ I. Diez-perez, P. Gorostiza, F. Sanz, and C. Müller, J. Electrochem. Soc., 2001, 148, B307.

${ }^{25}$ D. Fiorani, Surface Effects on Magnetic Nanoparticles, edited by Kluwer Academic Publishers, 2005. 